\title{
Emerging Technologies and Developments in Cloud Computing: A Systematic Review
}

\author{
Fakhrun Jamal ${ }^{1}$, Dr. Rafiqul Zaman Khan ${ }^{2}$ \\ ${ }^{1}$ Research Scholar, Department of Computer Science, A.M.U, Aligarh-202002, India, jml2864@gmail.com \\ ${ }^{2}$ Professor and Chairman, Department of Computer Science, A.M.U, Aligarh-202002, India, rzk32@yahoo.co.in
}

\begin{abstract}
For many organizations, cloud computing is an adoptable technology with its dynamic nature of flexibility and usage of virtualized resources as services over the Internet. Because of this, it mostly impacts the IT industry and the academia. It is an exceptional alternative for both IT industry and academia to operate their information systems efficiently without spending more capital on computers and network devices, particularly under budget shortage. In this paper, we reveal advance review focusing on cloud computing concept including definition, history, characteristics, service models, deployment model, benefits and challenges. Furthermore, cloud computing architecture, cloud computing technologies and production, cloud computing applications in Indian context and motivation towards cloud in recent time are also discussed. This paper can be very helpful for new researcher of this field and who is interested in knowing what it is going on recently in cloud computing.
\end{abstract}

Key words: History of cloud computing, Cloud Models, Cloud architecture, recent Cloud technologies, Cloud based Applications, Challenges, Motivation towards Cloud.

\section{INTRODUCTION}

Cloud computing is an evolving and innovative computer mechanism that uses distant servers and the Internet to manage software as well as data for potential platforms. Cloud uses virtualization technology, multi-tenancy, web services [2], etc. to provide infrastructure over the Internet. For the creation of Software as a Service (SaaS) application multi-tenancy is essential. Multi-tenancy leases multiple applications share the same software platform. Virtualization offers the abstraction of autonomous hardware accessibly to every Virtual Machine (VM) program that uses web services to communicate over the Internet.

Cloud computing services can help researchers in science and engineering use resources in demands, expand their research productivity, raising computational cost and deliver improved results. Service providers are focused on providing resources based on requirement to fulfil the quality of service (QoS) necessities. For cloud computing, the term QoS refers to the degree of availability, consistency and efficiency provided by platform and infrastructure, and an application that host it. Cloud users, who imagine cloud providers to offers the eminence features, and cloud providers, who involve finding right trade-offs between operating QoS and costs rates, are critical. Nonetheless, determining ideal trade-off is a tough choice issue, often disturbed through the existence of SLA defining service-level objectives and economic penalties associated with service-level agreement (SLA) violations [5].

Rest of paper arranged in the following way: Section 2 gives the of cloud computing overview including definition, history, characteristics, cloud models, benefits as well as challenges. In section 3, Architecture of cloud computing are discussed. Cloud computing Technologies and productions are also discussed in section 4 . In section 5, we define most popular business cloud applications in details. Applications of cloud computing based on Indian context are presented in section 6 and also highlights the motivation towards cloud in recent time in section 7. Finally, presents conclusion in section 8 .

\section{CLOUD COMPUTING OVERVIEW}

This section provides a general cloud computing overview with relative concept including its definition, history and compression.

\subsection{Definition}

Cloud computing has become one of the most dominant technology to achieve substantial scale and difficult computing in the last decade. Cloud Computing provide resources such as Storage, application and services on demand pay as use concept [1] [2]. Users don't need to maintain the expensive resources.

Cloud computing relates to the resources distributed over the internet as services. Because of on demand infrastructure it provides computing resources as an elastic service [5]. Without any doubt cloud computing becomes more important and used technology. It is not a technology but new grand approach in electronic commerce, academia and research [3] [4]. It is proven an inexpensive green technology for small to higher companies or business.

NIST Cloud Computing definition - "Cloud computing is model for enabling convenient, on demand network access to 
Fakhrun Jamal et al., International Journal of Emerging Trends in Engineering Research, 8(3), March 2020,894 - 905

a shared pool of configurable computing resources (e.g. network server application and services) that can be rapidly

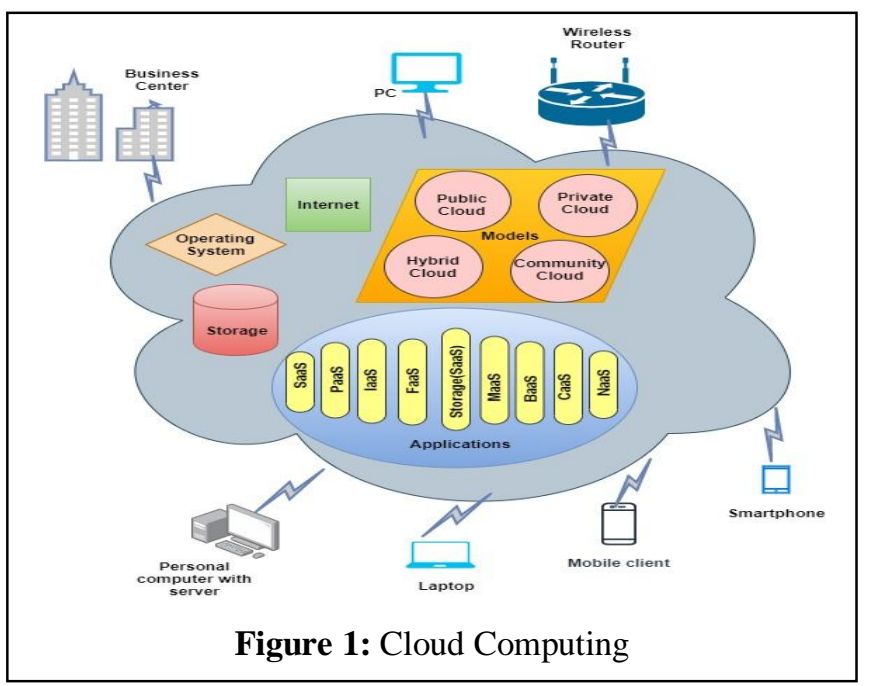

provisioned and released with minimal management effort" [6] clearly depicted in Figure 1.

\subsection{Cloud Computing History}

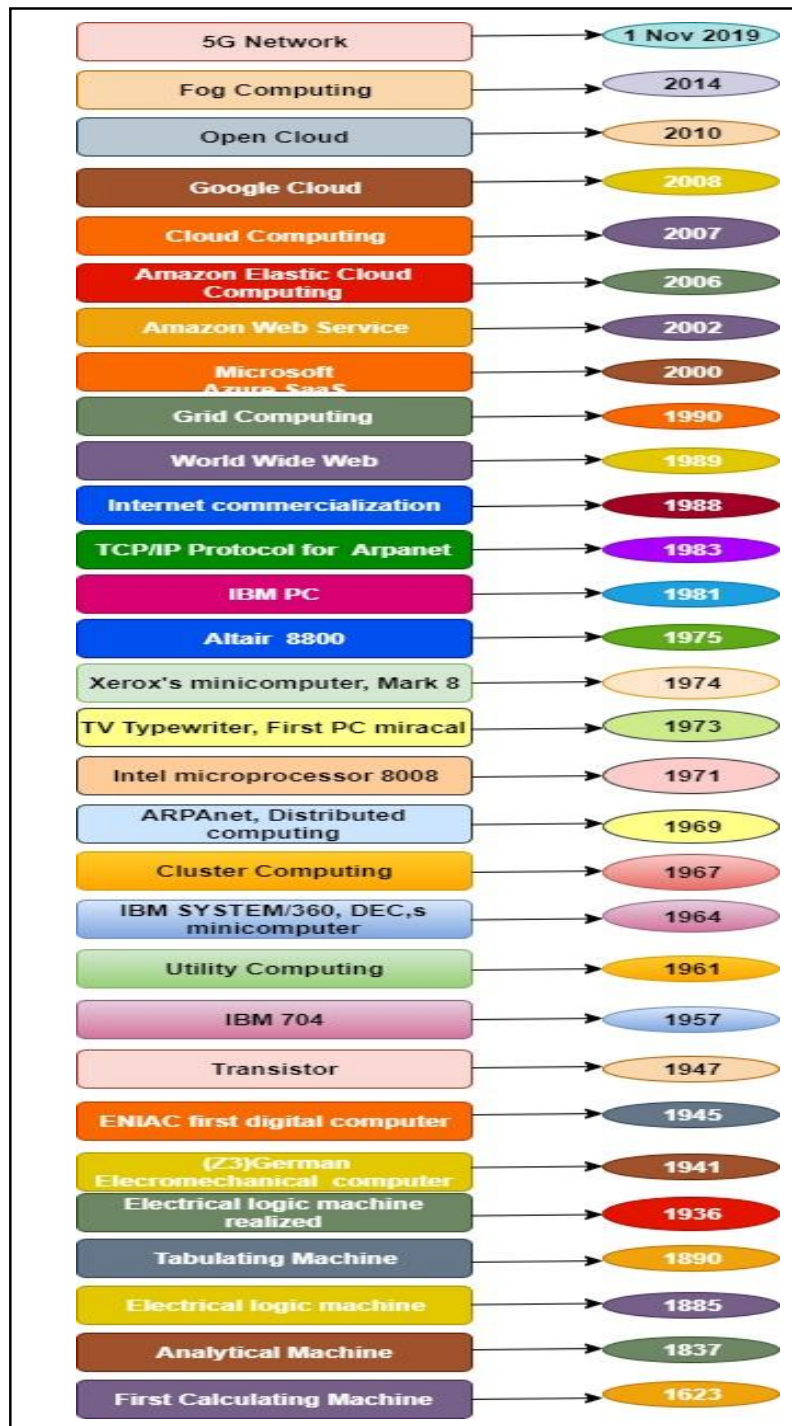

Figure 2: Cloud computing History
In the 1960s J.C.R.licklider invented cloud computing from ARPANET [10]. Some times before to access the information and to use the resources a user required infrastructure and computer system at the same place as data storage. When cloud computing took birth, it changed the world with a strong backbone of virtualization [9]. Several scientists developed cloud computing technology, and Youseff et al. were the first to provide cloud computing and its mechanisms with an understanding of that. Cloud computing, they say, is a mixture of some old and new ideas [7]. Cloud computing is the mainstream technology of the existing technology and internet techniques. It began its journey with parallel computing after it came into being at Distributed [8], Utility, Cluster, Grid then Cloud Computing.

Now, we discuss the comparative study of various technologies of computing in Table 1. involved in a cloud computing evolution.

\subsection{Cloud Computing Characteristics}

National Institute of Standards and Technology (NIST) exposed five characteristics of cloud computing.

\section{A. Broad network access}

Resources always remain available over the internet user can use them globally through devices such as mobile, laptop desktop etc. [10].

\section{B. On demand self-service}

Consumer can access resources of computing like storage, application, CPU etc. whenever he wants without the interference of human being [8].

\section{Rapid elasticity}

Elasticity is the efficiency of expanding or shrinking the computing resources in real time, depending on the computing requirements of the consumer. Resources may be supplied despite of service provider involvement and may be swiftly scaled in or scale-out as needed by the user [4, 24].

\section{Resource pooling}

Computing resources from providers are pooled to assist all customers by a multi-tenant model, with various physical as well as VMs being dynamically allocated and reallocated allowing to user request [28].

\section{E. Measured service}

In cloud system services are provided as pay-per-use concept, so that cloud system observe and control automatically of utilized services by user and service provider.

There are some other characteristics found by some researchers. 
Fakhrun Jamal et al., International Journal of Emerging Trends in Engineering Research, 8(3), March 2020,894 - 905

Table 1: Comparative study of various technologies of computing [8, 10-16]

\begin{tabular}{|c|c|c|c|c|c|c|}
\hline $\begin{array}{l}\text { S. } \\
\text { No. }\end{array}$ & Features & Distributed & Utility & Cluster & Grid & Cloud \\
\hline 1 & Operating System & $\begin{array}{l}\text { Windows or } \\
\text { Linux }\end{array}$ & $\begin{array}{l}\text { Linux } \\
\text { through } \\
\text { Windows } \\
\text { and Solaris }\end{array}$ & $\begin{array}{l}\text { Linux and } \\
\text { Windows }\end{array}$ & $\begin{array}{l}\text { No restriction is } \\
\text { made on the OS. }\end{array}$ & $\begin{array}{l}\text { Multiple OS } \\
\text { can run }\end{array}$ \\
\hline 2 & $\begin{array}{l}\text { Number of } \\
\text { servers }\end{array}$ & $100 \mathrm{~s}$ or $1000 \mathrm{~s}$ & $100 \mathrm{~s}$ & $100 \mathrm{~s}$ & $1000 \mathrm{~s}$ & $\begin{array}{l}\text { Varies from } \\
100 \mathrm{~s} \text { to } 1000 \mathrm{~s}\end{array}$ \\
\hline 3 & $\begin{array}{l}\text { System } \\
\text { performance }\end{array}$ & Complex & Improves & Improves & Improves & Improves \\
\hline 4 & Loose coupling & Yes & No & No & Both & Yes \\
\hline 5 & Protocol/API & MPI and NFS & & $\begin{array}{l}\text { Parallel Virtual } \\
\text { as well as MPI }\end{array}$ & $\begin{array}{l}\text { GRAM, MPI, } \\
\text { GIS and } \\
\text { MPICHG }\end{array}$ & $\begin{array}{l}\text { SOAP, REST } \\
\text { and TCP/IP }\end{array}$ \\
\hline 6 & Allocation & Decentralized & Centralized & Centralized & Decentralized & Centralized \\
\hline 7 & Cost of switching & High & Low & Low & Low & High \\
\hline 8 & $\begin{array}{l}\text { Data locality } \\
\text { exploited }\end{array}$ & Yes & No & No & No & Yes \\
\hline 9 & Inexpensive & No & Yes & No & No & Yes \\
\hline 10 & Business model & Yes & Yes & No & No & Yes \\
\hline 11 & $\begin{array}{l}\text { Service License } \\
\text { Agreement (SLA) }\end{array}$ & Limited & Limited & Limited & Yes & Yes \\
\hline 12 & $\begin{array}{l}\text { Service Oriented } \\
\text { Architecture } \\
\text { (SOA) }\end{array}$ & Yes & Yes & No & Yes & Yes \\
\hline 13 & Size of task & Small & Large & Single to large & Single to large & $\begin{array}{l}\text { Small and } \\
\text { medium }\end{array}$ \\
\hline 14 & Population & $\begin{array}{l}\text { Commodity } \\
\text { computer and } \\
\text { server }\end{array}$ & $\begin{array}{l}\text { Commodity } \\
\text { computer and } \\
\text { server }\end{array}$ & $\begin{array}{l}\text { Commodity } \\
\text { computer }\end{array}$ & $\begin{array}{l}\text { High end system } \\
\text { (cluster server) }\end{array}$ & $\begin{array}{l}\text { Power PCs, } \\
\text { data connected } \\
\text { to network of } \\
\text { high-end } \\
\text { servers }\end{array}$ \\
\hline 15 & Ownership & Multiple & Single & Single & Multiple & Single \\
\hline 16 & QoS guarantees & $\begin{array}{l}\text { High support } \\
\text { for best } \\
\text { performance }\end{array}$ & $\begin{array}{l}\text { Limited } \\
\text { support }\end{array}$ & $\begin{array}{l}\text { High support for } \\
\text { best performance }\end{array}$ & $\begin{array}{l}\text { Limited } \\
\text { resources and } \\
\text { often full effort }\end{array}$ & $\begin{array}{l}\text { Limited } \\
\text { assistance, } \\
\text { geared towards } \\
\text { availability }\end{array}$ \\
\hline 17 & Virtualization & Yes & Half & Half & Half & Must required \\
\hline 18 & Speed & $\begin{array}{l}\text { Elevated } \\
\text { bandwidth }\end{array}$ & $\begin{array}{l}\text { Elevated } \\
\text { bandwidth }\end{array}$ & $\begin{array}{l}\text { Elevated } \\
\text { bandwidth }\end{array}$ & $\begin{array}{l}\text { Lower } \\
\text { bandwidth }\end{array}$ & $\begin{array}{l}\text { Elevated } \\
\text { bandwidth }\end{array}$ \\
\hline 19 & Scalability & $\begin{array}{l}\text { Yes: The } \\
\text { consumers and } \\
\text { the resources }\end{array}$ & Yes & No & $\begin{array}{l}\text { Half: sites as } \\
\text { well as nodes }\end{array}$ & $\begin{array}{l}\text { Yes: hardware, } \\
\text { sites and nodes }\end{array}$ \\
\hline 20 & Failures control & $\begin{array}{l}\text { Limited } \\
\text { control over } \\
\text { failure } \\
\text { management } \\
\end{array}$ & $\begin{array}{l}\text { Limited } \\
\text { control over } \\
\text { failure } \\
\text { management } \\
\end{array}$ & $\begin{array}{l}\text { Limited control } \\
\text { over failure } \\
\text { management }\end{array}$ & $\begin{array}{l}\text { Limited control } \\
\text { over failure } \\
\text { management }\end{array}$ & $\begin{array}{l}\text { Strong failure } \\
\text { management }\end{array}$ \\
\hline 21 & Privacy & High Standard & $\begin{array}{l}\text { Service } \\
\text { Standard }\end{array}$ & $\begin{array}{l}\text { Medium } \\
\text { Standard }\end{array}$ & $\begin{array}{l}\text { Medium } \\
\text { Standard }\end{array}$ & High Standard \\
\hline 22 & Security & $\begin{array}{l}\text { Standard login } \\
\text { based on } \\
\text { password }\end{array}$ & $\begin{array}{l}\text { Standard } \\
\text { login based } \\
\text { on password }\end{array}$ & $\begin{array}{l}\text { Standard login } \\
\text { based on } \\
\text { password }\end{array}$ & $\begin{array}{l}\text { Public / private } \\
\text { key } \\
\text { authentication } \\
\text { based on pair }\end{array}$ & $\begin{array}{l}\text { A virtual } \\
\text { machine is } \\
\text { provided for } \\
\text { every user / } \\
\text { program. }\end{array}$ \\
\hline 23 & Transparency & Yes & Yes & Yes & No, Low & $\begin{array}{l}\text { Yes, elevated } \\
\text { but optional }\end{array}$ \\
\hline
\end{tabular}


Fakhrun Jamal et al., International Journal of Emerging Trends in Engineering Research, 8(3), March 2020, 894 - 905

\begin{tabular}{|c|c|c|c|c|c|c|}
\hline 24 & Capability & $\begin{array}{l}\text { Based on } \\
\text { Product use }\end{array}$ & $\begin{array}{l}\text { Based on a } \\
\text { provision of } \\
\text { service }\end{array}$ & $\begin{array}{l}\text { Guarantee and } \\
\text { Stable }\end{array}$ & Varies but high & $\begin{array}{l}\text { Based upon a } \\
\text { market } \\
\text { specification }\end{array}$ \\
\hline 25 & $\begin{array}{l}\text { Resource } \\
\text { management }\end{array}$ & Distributed & Distributed & Centralized & $\begin{array}{l}\text { Decentralized } \\
\text { organization and } \\
\text { virtual } \\
\text { organization }\end{array}$ & $\begin{array}{l}\text { Centralized or } \\
\text { delegable to } \\
\text { third parties }\end{array}$ \\
\hline 26 & Composition & $\begin{array}{l}\text { Ideal PC and } \\
\text { server }\end{array}$ & $\begin{array}{l}\text { PC and server } \\
\text { Specifications }\end{array}$ & Ideal PC & $\begin{array}{l}\text { Servers to the } \\
\text { high end }\end{array}$ & $\begin{array}{l}\text { Ideal PC, } \\
\text { Server and } \\
\text { NAC }\end{array}$ \\
\hline 27 & Product pricing & Limited & $\begin{array}{l}\text { Pricing for } \\
\text { utilities } \\
\text { instead of flat } \\
\text { rates }\end{array}$ & $\begin{array}{l}\text { Not for open } \\
\text { market but also } \\
\text { limited }\end{array}$ & $\begin{array}{l}\text { Dominated by } \\
\text { private or public } \\
\text { interest }\end{array}$ & $\begin{array}{l}\text { Pricing of the } \\
\text { utilities } \\
\text { discounted for } \\
\text { the larger } \\
\text { clients. }\end{array}$ \\
\hline 28 & Multi-tenancy & No & No & No & Yes & Yes \\
\hline 29 & Reliability & Half & No & Less & Medium & High \\
\hline 30 & User friendly & No & No & No & Half & Yes \\
\hline 31 & Self service & No & No & No & Yes & Yes \\
\hline 32 & Nodes' location & $\begin{array}{l}\text { No need to be } \\
\text { same physical } \\
\text { location }\end{array}$ & $\begin{array}{l}\text { No need to be } \\
\text { same } \\
\text { physical } \\
\text { location }\end{array}$ & $\begin{array}{l}\text { Physically in the } \\
\text { same Location }\end{array}$ & $\begin{array}{l}\text { Distributed } \\
\text { overall the globe }\end{array}$ & $\begin{array}{l}\text { Location does } \\
\text { not matter }\end{array}$ \\
\hline 33 & $\begin{array}{l}\text { Homogeneous / } \\
\text { heterogeneous }\end{array}$ & Homogenous & $\begin{array}{l}\text { Heterogeneo } \\
\text { us }\end{array}$ & Homogeneous & Heterogeneous & Heterogeneous \\
\hline 34 & Internet & Not required & Not required & $\begin{array}{l}\text { No internet } \\
\text { access }\end{array}$ & $\begin{array}{l}\text { Yes internet } \\
\text { required }\end{array}$ & $\begin{array}{l}\text { Yes internet } \\
\text { required }\end{array}$ \\
\hline 35 & Interoperability & Yes & Yes & Yes & Yes & No \\
\hline 36 & $\begin{array}{l}\text { Application } \\
\text { drivers }\end{array}$ & $\begin{array}{l}\text { E-commerce } \\
\text { including } \\
\text { e-banking }\end{array}$ & $\begin{array}{l}\text { Web hosting } \\
\text { service, web } \\
\text { app }\end{array}$ & $\begin{array}{l}\text { Company, } \\
\text { enterprise data } \\
\text { centre } \\
\text { computing }\end{array}$ & $\begin{array}{l}\text { High-performan } \\
\text { ce research } \\
\text { collaboration }\end{array}$ & $\begin{array}{l}\text { Web-app } \\
\text { distribution of } \\
\text { material, } \\
\text { dynamic } \\
\text { location }\end{array}$ \\
\hline 37 & $\begin{array}{l}\text { Service } \\
\text { negotiation }\end{array}$ & Limited & $\begin{array}{l}\text { Utility } \\
\text { oriented and } \\
\text { not flat }\end{array}$ & $\begin{array}{l}\text { Not for open } \\
\text { market but also } \\
\text { limited }\end{array}$ & SLA based & SLA based \\
\hline 38 & Application & $\begin{array}{l}\text { Geographicall } \\
\text { y dispersed }\end{array}$ & $\begin{array}{l}\text { Business } \\
\text { model }\end{array}$ & HP and,HTC & $\begin{array}{l}\text { HPC, HTC and } \\
\text { Batch }\end{array}$ & $\begin{array}{l}\text { SME } \\
\text { interactive } \\
\text { apps }\end{array}$ \\
\hline 39 & Example & $\begin{array}{l}\text { www, peer to } \\
\text { peer network, } \\
\text { real time } \\
\text { process control }\end{array}$ & $\begin{array}{l}\text { Google, } \\
\text { Amazon } \\
2008\end{array}$ & $\begin{array}{l}\text { VAXcluster, } \\
\text { ARCnet }\end{array}$ & $\begin{array}{l}\text { SETI, GIMPS, } \\
\text { Tera grid and } \\
\text { NKN }\end{array}$ & Amazon EC2 \\
\hline 40 & Future & $\begin{array}{l}\text { Cloud, Grid, } \\
\text { Cluster and } \\
\text { Utility } \\
\text { computing }\end{array}$ & $\begin{array}{l}\text { Cloud and } \\
\text { Grid } \\
\text { computing }\end{array}$ & Grid Computing & $\begin{array}{l}\text { Cloud } \\
\text { computing }\end{array}$ & $\begin{array}{l}\text { Mobile as well } \\
\text { as cloud } \\
\text { computing for } \\
\text { next generation }\end{array}$ \\
\hline
\end{tabular}

\section{F. $\quad$ Unlimited storage}

Cloud computing is a data storage model in which digital data is stored in the logical pool, cloud storage provider are responsible for keeping up the data accessible and available. People and organization buy or lease the storage as they need.

\section{G. Flexibility}

Cloud computing provides a flexible solution to the cloud users for data storage and accessing the resources any time anywhere over the internet using the mobile, computer and other devices.

\section{H. Reliability}

It provides the services $24 / 7$ to users. User can take benefits of services from everywhere every time in the condition of the internet. 
Fakhrun Jamal et al., International Journal of Emerging Trends in Engineering Research, 8(3), March 2020, 894 - 905

\section{Inexpensive}

As we recognize that cloud computing is wage as use model. User can be beneficial for renting the infrastructure form cloud provider. User does not need to worry of maintenance or extra charges of services.

\section{J. Universality}

Cloud computing is also called a ubiquitous computing because services are available all the time globally and any user can use services through the devices over the internet. Services which are available on the cloud are not custom make for a particular service. User can select a variety of application at the same time. Different user can run different applications at the same time.

\subsection{Cloud Computing Service Models}

There are some service models that provide the specific services to the customer as shown in Figure 3.

\section{A. Software as a Service (SaaS)}

This model is recognized as a software delivery model actually; it provides the license of the software applications to the users of cloud computing. Software applications can be used or accessible through the internet using the devices. Users do not require to maintain or installation of such application.

Example: Gmail, yahoo, Facebook etc. [21].

\section{B. Platform as a Service (PaaS)}

This model is commonly used by developers to develop their applications on the rental platform of cloud computing. It offers deployment of applications by reducing the cost of maintenance of hardware and software. SaaS only host completed cloud applications whether PaaS offers to complete the incomplete software.

Example: Google App Engine [8, 21].

\section{Infrastructure as a Service (IaaS)}

The model offers an overall cloud computing platform on the internet, meaning cloud users can set up their operating system and cloud provider control the memory, CPU and processing of the system. It offers a virtual server, storage, network hardware and operating system. Consumer pays only for consumed resources.

Example: Amazon Elastic Compute Cloud (EC2) [8, 21].

Some other types of service are more generally known as Anything as a Service (AaaS) being:

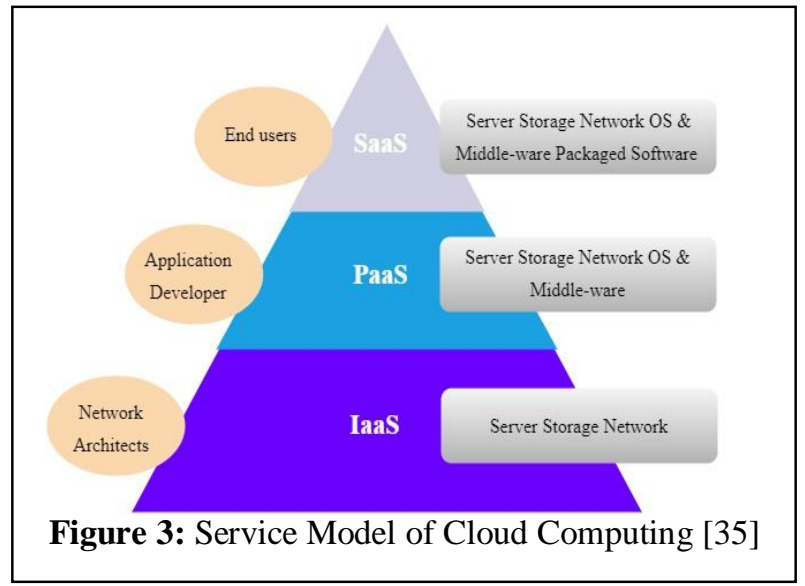

\section{Function as a Service (FaaS)}

Under the general term Server-less Computing, function as a service ( $\mathrm{FaaS})$ is associated, but the term may be used interchangeably. This model called service hosted a remote procedure call to enable individual functions to be deployed in the cloud running in response to events [22].

\section{E. Mobile "backend" as a Service (BaaS)}

BaaS has a mobile app and web app developers are serviced with a cloud storage solution to connect their devices to. Services provide customer monitoring, request confirmation, social networking incorporation and more [22].

\section{F. Monitoring as a Service (MaaS)}

This model monitors the state online of all the functionalities of services and applications, software, network, system and any element that deployed for users within the cloud. It provides the facility to users of state monitoring at different levels of cloud service.

\section{G. Communication as a Service (CaaS)}

CAAS is a solution for outsourced corporate communications that can be rented from a single supplier. These communications may include Instant Messaging (IM), Voice over IP (VoIP), applications for collaboration and video conferencing via fixed and mobile devices. The manufacturer of CAAS is responsible for all hardware and software operations and provides assured service quality (QoS). CAAS allows companies to selectively deploy devices and modes of communication on a pay-as-you-go concept, as needed [29].

\section{H. Network as a Service (NaaS)}

NAAS is a new model of cloud computing in which customers have access to additional computing resources with switch and router. NAAS may include elastic and comprehensive VPN (Virtual Private Network), protocols for multicast, bandwidth on-demand, security firewall, custom routing, detection and prevention of intrusion, content monitoring, filtering and antivirus. 
Fakhrun Jamal et al., International Journal of Emerging Trends in Engineering Research, 8(3), March 2020, 894 - 905

\subsection{Deployment Model of Cloud Computing}

There are most popular and important models of cloud computing as depicted in Figure 4 and comparative study in Table 2 .

\section{A. Public Cloud}

This model offers the services such as applications, software and storage to the users or any organization over the internet without any restriction to use them. Here services may be less secure, but users are free to use the services [8]. The infrastructure of a private model is made general public [21].

\section{B. Private Cloud}

Private clouds are called internal clouds. [6] The infrastructure of the private cloud is available only for specific authorized user or organization. Only internal user can use the resources. It is more secure then public cloud because only internal consumer can access the facilities. All the resources are maintained and govern by the organization itself $[30,10]$.

\section{Hybrid Cloud}

This cloud infrastructure is formed by a combining of public and private cloud that is called hybrid, private and public clouds are clutched within a standard protocol. This model provides pliancy more than public and private cloud and has a higher control over the applications in the infrastructure [6, 24].

\section{Community Cloud}

In this model, similar types of requirements of organizations share the infrastructure of community cloud. Using the resources commonly there is made a data centre by service provider where services are avail for the specific users and organization. This type of cloud is less expensive than private cloud and more secure $[21,11]$.

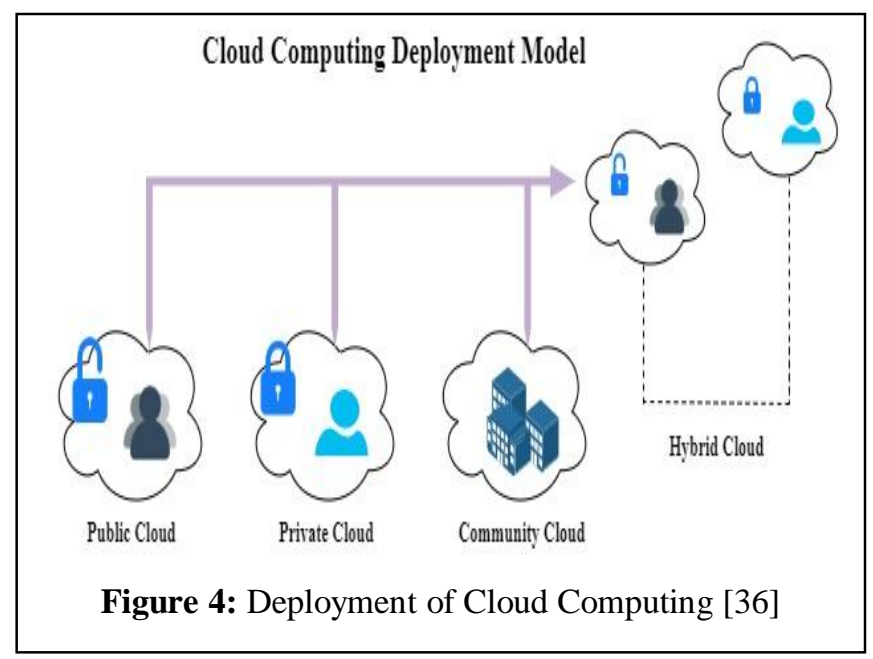

Table 2: Comparative study of Deployment Model [8, 10, 17].

\begin{tabular}{|c|c|c|c|c|}
\hline Attributes & Public & Private & Community & Hybrid \\
\hline $\begin{array}{l}\text { Simple to install and } \\
\text { use }\end{array}$ & Easy & $\begin{array}{l}\text { Needs the IT } \\
\text { expertise }\end{array}$ & $\begin{array}{l}\text { Needs the IT } \\
\text { expertise }\end{array}$ & $\begin{array}{lll}\begin{array}{l}\text { Needs } \\
\text { expertise }\end{array} & \text { the } & \text { IT } \\
\end{array}$ \\
\hline $\begin{array}{l}\text { Security and data } \\
\text { protection }\end{array}$ & Low & High & $\begin{array}{l}\text { High } \\
\text { Comparatively to } \\
\text { other }\end{array}$ & High \\
\hline Controlling data & Little to none & High & $\begin{array}{l}\text { High } \\
\text { Comparatively to } \\
\text { other }\end{array}$ & $\begin{array}{l}\text { High Comparatively } \\
\text { to other }\end{array}$ \\
\hline Reliability & Susceptible & Extraordinary & $\begin{array}{l}\text { Comparatively } \\
\text { high }\end{array}$ & Extraordinary \\
\hline $\begin{array}{l}\text { Scalability and } \\
\text { flexibility }\end{array}$ & Extraordinary & Extraordinary & Stable capacity & Extraordinary \\
\hline Cost-efficiency & $\begin{array}{l}\text { The lowest of } \\
\text { those }\end{array}$ & $\begin{array}{l}\text { The } \\
\text { cost-intensive, the } \\
\text { costliest }\end{array}$ & $\begin{array}{l}\text { The costs are } \\
\text { shared } \\
\text { members of the } \\
\text { Community }\end{array}$ & $\begin{array}{l}\text { Less expensive than } \\
\text { a private model but } \\
\text { more expensive than } \\
\text { a public one }\end{array}$ \\
\hline $\begin{array}{l}\text { Request for } \\
\text { Hardware in-house }\end{array}$ & No & Is based on & Is based on & Is based on \\
\hline Workload & $\begin{array}{lr}\text { Suitable for } \\
\text { control large } \\
\text { workload nodes }\end{array}$ & $\begin{array}{lr}\text { Unsuitable for } \\
\text { control large } \\
\text { workload nodes }\end{array}$ & $\begin{array}{lr}\text { Suitable for } \\
\text { control large } \\
\text { workload nodes }\end{array}$ & Dynamic \\
\hline Size of datacenter & Probably 50,000s & Probably $50,000 \mathrm{~s}$ & $\begin{array}{l}\text { Public } \\
\text { cloud }>15000> \\
\text { private cloud }\end{array}$ & $\begin{array}{l}\text { Less than private } \\
\text { cloud }\end{array}$ \\
\hline Ownership & $\begin{array}{l}\text { Owned } \\
\text { customers }\end{array}$ & $\begin{array}{l}\text { Owned by single } \\
\text { organization }\end{array}$ & $\begin{array}{l}\text { Owned by two or } \\
\text { more like-minded }\end{array}$ & $\begin{array}{l}\text { It is partly owned by } \\
\text { service providers }\end{array}$ \\
\hline
\end{tabular}


Fakhrun Jamal et al., International Journal of Emerging Trends in Engineering Research, 8(3), March 2020, 894 - 905

\begin{tabular}{|c|c|c|c|c|}
\hline & & & organizations & $\begin{array}{l}\text { and partly by } \\
\text { customers }\end{array}$ \\
\hline Virtualization & $\begin{array}{lr}\text { Optimization } & \text { of } \\
\text { resources } & \text { via } \\
\text { server } & \\
\text { virtualization } & \\
\end{array}$ & $\begin{array}{lr}\text { Optimization } & \text { of } \\
\text { resources } & \text { via } \\
\text { server } & \\
\text { virtualization } & \\
\end{array}$ & $\begin{array}{lr}\text { Efficiency } & \text { of } \\
\text { utilization } & \text { by } \\
\text { virtualization } & \text { of } \\
\text { servers } & \\
\end{array}$ & $\begin{array}{l}\text { Optimization of } \\
\text { resources via server } \\
\text { virtualization }\end{array}$ \\
\hline Maintenance cost & Lowest & Highest & Highest & Average \\
\hline Accessibility & Unlimited & Limited access & $\begin{array}{l}\text { Depends on no of } \\
\text { cooperatives }\end{array}$ & $\begin{array}{l}\text { Medium } \\
\text { accessibility }\end{array}$ \\
\hline Performance & Low /medium & Excellence & Very good & Good \\
\hline Cloud bursting & Not supported & Not supported & Not supported & Supported \\
\hline Example & Amazon EC2 & Microsoft azure & $\begin{array}{l}\text { Microsoft } \\
\text { government } \\
\text { community cloud }\end{array}$ & $\begin{array}{l}\text { Rackspace hybrid } \\
\text { cloud }\end{array}$ \\
\hline
\end{tabular}

\subsection{Cloud Computing Benefits}

Benefits of cloud computing is described here as follows:

\section{A. Non Functional}

- Simplicity: user does not need deep knowledge to use cloud services.

- Reliability: There is a little bit chance of failure if fails recovery is so fast.

- Quality of services (QoS): it means services are provided best to satisfy the user's requirement.

- Availability: Services are available 24/7.

- Elasticity: resources can be accessed easily and modified as a requirement.

- Mobility: services are available on the internet so the user can access anywhere any time.

\section{B. Economical}

- Cost Reduction: services of the cloud have cost reducible if the user doesn't need to buy or maintain expensive software.

- Pay per use: service provider charges only for used services.

- Green Environment: During the resources sharing it consumes the small amount of power to reduce the carbon emission.

\section{Technological}

- Virtualization: Here, single physical resource works as multiple virtual resources. The single physical resource creates a multiple execution environments and abstracts its physical properties from other systems. Physical resources are as an operating system (OS), storage devices, network or server.

- Multi-tenancy: It means that multiple users can access the cloud resources at a time.

- Security and Privacy: Here, our data remains secure from unauthorized users.
- Data Management: in cloud computing our, data stored and managed in large amount by providing quick access.

- Tools: To setup the cloud environment many tools are implemented.

\section{Cloud Provider's point of view}

Cloud provider says that recently all the existing data centers are underutilized. They are mostly $15-20 \%$ utilized. So large companies can take benefit by renting the rest to other companies and also make available all resources of the cloud for running data centre properly. A small type of business adopts this at very minimal cost.

\section{E. Cloud User's point of view}

Here user says that the user does not require looking after of hardware and software what he uses and doesn't to worry about maintenance. Cloud consumers use demand-based resources and only pay for usage. Users are not long tied with the traditional system. User can switch easily.

\subsection{Cloud Computing Challenges}

\section{A. Load Balancing}

Load balancing is a mechanism to stop the system failure. So it's a big challenge of cloud computing. In cloud computing infrastructure, when lots of demand for services hit on the server, then the system becomes overloaded. Load balancers distribute the load over all nodes equally to reduce the load to make the system smooth [34].

\section{B. Performance}

According to the survey, performance is also a big problem in cloud computing. Healthy performance must be offered to the user when a user access cloud resources. Performance is measured by the overall efficiency of running applications on the system. Whenever a user wants more services from more the one cloud like as something from private cloud and something from hybrid or the pubic cloud, then it becomes a challenge to manage and serve the excellent performance of service. 
Fakhrun Jamal et al., International Journal of Emerging Trends in Engineering Research, 8(3), March 2020, 894 - 905

\section{Security}

Cloud computing has dynamic scalability, virtualization and multi-tenancy features. Security is a big issue when data and applications move from one to another network. Various types of applications and data that move on the different servers so, it is difficult to address the security. [4, 24].

\section{Interoperability}

Interoperability means that the same rules are applicable on different cloud platforms. Cloud must have the flexibility of moving or switching whenever the user wants without the lock-in period for vendor. Here is found that lack of open principles, standard APIs and interfaces. It is the adoption resistance of cloud computing interoperability.

\section{E. Migration}

Migration is the time consuming issue, whenever a user wants to migrate from one cloud to another or one hosting facility provider has to aspect some other issues. It is not an informal task to move because in this process, work or business will stop for some hours/days [10].

\section{F. Energy management}

Energy is consumed [8] in cloud computing using the resources. Whenever high demand for resources of cloud computing then datacenters are unzipped in large amount which needs a big amount of power. But power consumption must be optimized for betterment.

Some other future issues, challenges and trends in cloud computing.

\section{G. Internet of Things (IoT)}

In cloud computing, IoT devices are definitely a potential phenomenon. IoT is a smart and intelligent technology where sensors are used. The IoT definition changes as the time of cloud computing comes "IoT= Cloud computing + Ubiquitous network + Intelligent sensing network" [25]. Making the atmosphere smart lots of use of sensors like a smart home guard, smart bulb, and smart switch everywhere. Putting up the sensors in various areas railway, bridge, electricity grid, oil, gas pipe and appliances etc. and then connect all the things with internet to operate the certain programs to realize the remote control.

\section{H. $5 G$ Network}

There is huge amount of data produced through the various devices while handling this big data we need high speed of internet. This time IT organization looking forward to the high-speed network that is $5 \mathrm{G}$. It is tested some in various palaces in the world. Data is kept in the cloud so that the cloud needs a high speed of the internet to adopt this data easily.

\section{CLOUD COMPUTING ARCHITECTURE}

The cloud computing architecture is divided into two ends. First one is a front end and the second one is the backend. The front end defines the users who interact to the internet for using the cloud resources. The back end defines the working in the cloud like hardware, software and applications, datacenters, security and management are operating internally user doesn't know of it.

Normally, cloud architecture is categorized into layers like infrastructure, platform, application, security and management layers as shown in Figure 5.

\subsection{Application Layer}

This layer has the real cloud applications. This layer has various features for automatic application scaling to accomplish better availability, efficiency and less operating expenses. Web services business applications and multimedia etc. are available on this layer.

Example: Google Apps, Facebook, YouTube.

\subsection{Platform layer}

This layer consists of an operating system and application framework to operate any application efficiently. It is like a framework that provides the environment and user can be burden-free to deploy the applications.

Example: Google's app engine works on this layer to offer storage implementation backing for the API [26].

\subsection{Infrastructure layer}

Another name of the infrastructure layer is a virtualization layer. This layer provides lots of storehouse and computing resources by sectioning the physical resources by virtualization. It is an essential part of the architecture of cloud computing. Some functions, such as a dynamic assignment of resources, are rendered only by virtualization technology.

\subsection{Hardware layer}

This layer is ideal for handling physical resources such as servers, switches, control and refrigeration systems. Exemplary hardware layers implemented in datacenters. Typically a data centre implants lots of servers that are clustered in frames and interrelated via routers and switches [26].

\subsection{User/Client}

A cloud client or user interacts to the internet for using the services from the cloud through the devices.

Example: Smartphone, personal computer, operating system and other devices etc. 
Fakhrun Jamal et al., International Journal of Emerging Trends in Engineering Research, 8(3), March 2020,894 - 905

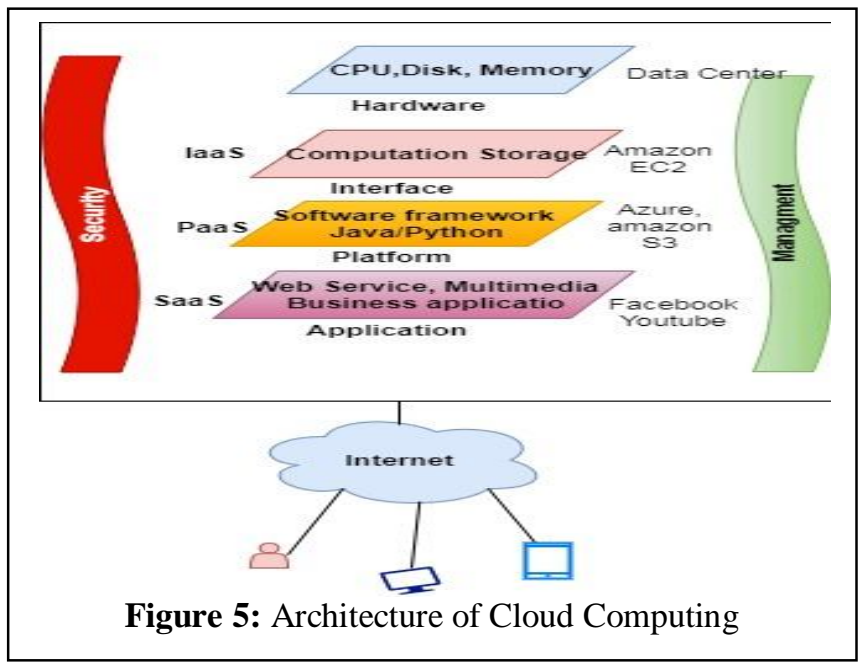

\section{CLOUD COMPUTING TECHNOLOGIES AND PRODUCTION}

We will describe a summary of the technologies used in cloud computing environments within this section.

\subsection{Architectural Design of Data Centre}

A data center covers lots of devices such as routers, switches and servers. The architecture design of the data centre is critical to find throughput and application performance in a distributed computing environment because of having a load of devices. Recently network architecture is design layered wise which had been established in some of the major datacenters. A simple layer of a data center is physically connected to the network where the server in racks is 20-40 servers per frame, each associated to a Gbps linked access switch. For redundancy of $10 \mathrm{Gbps}$ connections, the access device connects typically to two aggregation switches [27]. The aggregation layer provides important functionalities such as managing server load, location service, domain service and more. The main routers handle traffic to and from the data centre.

\subsection{Distributed File System over Cloud}

The Google File System (GFS) [28], evolved in late 1990s, by using thousands of storehouse systems, designed from economically objective components to confer petabytes of storage to a large user community with diverse needs [28]. It was developed especially convenient access to data using large clusters of objective servers [26]. Files are separated into the small parts that are called chunks and size of these chunks is 64 megabytes. GFS is developed for high data throughput, minimum latency and persist individual failures.

HDFS (Hadoop Distributed File System) gained inspiration from GFS and started to store large files across multiple machines. The file system consists of a bunch of data nodes $[26,1]$, each of which uses HDFS-specific block protocol [1, 26, 29].

4.3 Distributed application frame work over Cloud
Distributed file system or applications over the network are working based on Hadoop and MapReduce concept. These both terms are mainly used in big data system analysing the large data. Hadoop is an open file system. Open source MapReduce and Hadoop project are used in companies to run large data-intensive calculations. MapReduce is a programmable framework for software [31] based on java language presented by Google [26] to backing a large data set of distributed computing.

\section{POPULAR BUISNESS CLOUD APPS}

In this part, we describe various business applications that for their availability and reliability are gaining popularity day by day. In the IT market, there are some providers, of them Amazon Cloud Compute (EC2), Windows Azure, Google App Engine etc. are the most popular.

\subsection{Amazon S3 and EC2 Services}

Amazon is finding as to the first largest organization which provides cloud computing services on a large scale. Amazon found some resources idle then decided that idle resources should be rented to the other organizations not physically but on the internet [32]. Amazon developed a series of web services such as Amazon EC2, [18], simple storage service (S3) [26]. Amazon Elastic compute [33] cloud enables cloud users' server size selecting the configurable virtual machine such as disk size, processor speed and RAM size. The user would have to generate the instance to imply his changes, so that uploading suitable software can make changes and after completing the changes it will be a bunch of new machines. This feature offers the capability to put instances in multiple places. These sites are made of sections and regions.

Amazon S3 is a storage service that provides proposal data security, high availability, and performance. It means that all the customers and companies can use the storage to protect the data from the malicious program such as mobile applications, websites, and backup and restore data, IoT devices and analysis of big data. Amazon S3 offers a concept that is convenient to use management features while a user can organize the data in finely tuned. Amazon S3 is calculated for $99.99 \%$ of stability and store data for billions of applications for industries in the whole world. [34].

\subsection{Google-App-Engine}

Google App Engine [18] is a cloud computing platform for managing web applications within Google's existing infrastructure. Use up to a predefined applicable resource is easy to scale, handle and safe. It also supports Java and python to the evolution of JVM languages. In 2008 the first version of Google App Engine [6] was introduced as beta [20].

\subsection{Windows Azure}

Windows Azure is a service for cloud computing that Microsoft creates to design, test, deploy and manage applications and services via Microsoft's managed data centre. This improves various distinguishing programming 
Fakhrun Jamal et al., International Journal of Emerging Trends in Engineering Research, 8(3), March 2020, 894 - 905

frameworks, tools and languages [19] including applications and device unique to Microsoft and other parties [18].

Azure was initiated in Oct 2008 with the name "Project Red Dog" and in February 2010 came by the name "windows azure" [19].

\section{CLOUD COMPUTING APPLICATIONS IN INDIAN CONTEXT}

Cloud Computing can be used in rural areas for development for a best and easy life. If some applications are developed like as e-governance, e-banking etc. by using low-cost computing with best efficiency [37][38].

\subsection{E- Governance}

If the Indian government goes with the E-services that will be the big evolution. When all department of the government governed electronically, then all the services getting through the cloud computing than so there will not be charged extra, and this E-Governance would be the part of e-business. If E-Governance adopts technology, there are some impact such as $24 / 7$ service model means that services availability high, regularly updated information supply, trained human resources security and privacy also monitored [18].

\subsection{Rural developments}

It is an interface between government and business organization. Main purpose is to improve the service providing to the public efficiently. Some projects should be initiated for facilitating to the villages like E-Gram Panchayat, E-management for Paradhan information and data updated on the website that should be connected wireless internet connectivity. Through this Internet connectivity, all rural citizens can be facilitated surfing the internet to find any update of the rural jobs, land information, and other information regarding village. [18].

\subsection{Academic Libraries}

Cloud Computing is used in libraries for best service and enhancement of their data without growing the cost value [4].

\subsection{Biological research}

Cloud computing provides lots of tool one of them Bioinformatics tools are used in biological research in small, very expenditure. And applications and datasets are also can be used for image analysis.

\subsection{Document Processing}

Now it is easy to convert of a very large bunch of documents from one form to another form of encryption of the data using the services of cloud computing [4].

\subsection{Video Trans-coding}

Cloud computing is used to transfer the video to audio and audio to video format easily. Example: AVI to MPEG [4].

\subsection{Image Processing}

Application of image-processing is used to converting the format like create thumbnails or enlarging an image [4].

\subsection{Data mining}

Data mining means a large collection of information and cloud computing has the capability to large processing in a mini moment [4].

\subsection{Report generation}

Cloud services can be utilized for generating the report like manufacturing, retailing and another economic sector. Insurance company healthcare organizations and institutions are working daily for the transaction for generating the report for billing [4].

\subsection{Software Development}

Keeping the records of software development cloud computing is used to check automatic and verify the software [4].

\section{RECENT MOTIVATION TOWARDS CLOUD}

Cloud computing is not a new concept, but it is a development In recent time, cloud computing prompts in business and personal work are noticed for facility owed to some up-to-date technology developments and commercial models [39].

\subsection{Huge market for innovative application}

Application which are more accurate for timely response and capable of deliver information by non-human radars finding are more popular. This type of applications are normally more involved to the cloud not only for high obtainability but also for more acute data and needed analysing of data there on different sources. [18]. More common are the transmission of information by non-human sensors or by other users.

\subsection{Parallel batch processing}

Implicitly cloud facilitates batch processing, as well as proficiently analyses terabyte data. Models such as Yahoo! open-source and Google's map-reduce same Hadoop's can be used to mask the organizational complexities of lots of servers for cloud computing in parallel processing [18].

\subsection{New trend in entrepreneurship and science communities}

This time business enterprises are excited to know the customer's need, the interest of the pattern to buy, and service management of providing to make the best decision for organization and supply. This type of online data processing can be done very easily with the aid of the cloud. User's requirement is personalized on the user's website or desktop after recognize. A big example of it is Yahoo!'s homepage [18]. 


\subsection{Wide application for desktop}

Which applications like Matlab, Mathematical are falling compute compact so that a single computer is not efficient to execute them? So these are made to be able to execute comprehensive appraisal using cloud computing [18].

\section{CONCLUSION}

This study presented a systematic review of emerging technologies and developments in cloud computing. Cloud computing is on demand service which uses the pay per use concept to provide resources like computational platform, storage, servers. Cloud computing resources can contribute science and engineering scholars to use resources in demands, reduce cost of computing, improve research efficiency and provide better results. In this paper the deployment model and service model of cloud computing are also discussed, that helps in retrieving the information. We define the most popular business cloud applications in details and also applications of cloud computing based on Indian context are presented. Further, highlights the motivation towards cloud in recent time which helps the researchers to expand the knowledge of cloud computing.

\section{REFERENCES}

1. I.A. Targio Hashem, I. Yaqoob, N.B. Anwar, S. Mokhtae, A. Gani and S.U. Khan "The rise of big data on cloud computing: Review and research issues", Elsevier Information System Vol. 47, No. C, pp 98-115, January 2015. https://dl.acm.org/doi/10.1016/j.is.2014.07.006

2. K. Bilal, O. Khalid, A. Erbad and S.U. Khan "Potential, trends and prospects in technologies: Fog, cloudlet, mobile edge and micro data centre", Elsevier Computer Networks Vol. 130, No. 15 pp 94-120, January 2018.

DOI: https://doi.org/10.1016/j.comnet.2017.10.002

3. W.Y.C. Wang, A. Rashid and H.M. Chuang "Toward the trend of Cloud Computing”, Journal of Electronic Commerce Research, VOL.12, No 4, pp 238-242, 2011.

4. A. Jain and R. Kumar "A Taxonomy of Cloud Computing", International Journal of Scientific and Research Publications, Vol 4, Issue 7, pp. 1-5, July 214, ISSN 2250-3153.

5. N. Choupra, T. Singh and A. Kumar "Cloud Computing: A Review" International Journal of Computer Science and Technology, Vol.3, Issue 3, PP. 65-68, July-Sept 2012.

6. Q. Zhang, L. Cheng and R. Boutaba "Cloud Computing: state-of-the -art and research challenges", 2014 IEEE 8th International Conference on Application of Information and Communication Technologies (AICT) , PP 7-18, 2015. DOI: 10.1109/ICAICT.2014.7035932

7. R. Kour and A. Kour "A Review paper on Evolution of Cloud Computing, its Approaches and Comparison with Grid Computing", International Journal of
Computer Science and Information Technologies, Vol.5 (5), pp. 6060-6063,2014.

8. M. Haris and R. Z. Khan "A Systematic Review of Cloud Computing", International Journal of Computer Science and Engineering, Vol.6, Issue-11, pp. 632-639, Nov 2018.

9. G. Mittal, N. Kesswani and K. Goswami "A Survey of Current Trends in Distributed, Grid and Cloud Computing" International Journal of Advance Studies in Computer Science and Engineering, Vol.2, Issue.3, pp. 1-6, 2013.

10. M.O. Ahmad and R. Z. Khan "The Cloud Computing: A Systematic Review" International Journal of Innovative Research in Computer and Communication Engineering, Vol. 3, Issue. 5, pp. 79-83, May 2015.

11. N. Sadashiv and S.M.D. Kumar "Cluster, Grid and Cloud Computing: A Detailed Comparison" The 6th International Conference on Computer Science \& Education (ICCSE 2011), pp. 477-482 August 3-5, 2011. SuperStar Virgo, Singapore. DOI:10.1109/ICCSE.2011.6028683

12. I. Nwobodo, "Cloud Computing: A Detailed Relationship to Grid and Cluster Computing", International Journal of Future Computer and Communication, Vol. 4, No. 2, pp. 82-87, April 2015. doi: 10.7763/ijfcc.2015.v4.361

13. A. Patel, A. Seyfi, Y.Tew and A. Jaradat "Comparative study and review of Grid, Cloud, Utility Computing and Software as a Service for use by libraries", Library Hi Tech News, No. 3, pp. 25-32, , 2011.

14. H. AlHakami, H. Aldabbas and T. Alwada'n, "Comparison between Cloud and Grid Computing: Review paper", International Journal on Cloud Computing: Services and Architecture, Vol. 2, No. 4, pp. 1-21, August 2012. DOI: 10.5121/ijccsa.2012.2401

15. "Cloud Development models", Retrieved from URL https://www.sam-solutions.com/blog/four-best-cloud-de ployment-models-you-need-to-know/. Accessed in Nov 2019.

16. A. Ghosh, "Cloud Computing", M.Tech Seminar Report, Department of Computer Science and Engineering, Indian Institute of Technology, Bombay, Powai Mumbai. https://www.cse.iitb.ac.in/ abhirup09/Docs/cloud_comp uting_final_report.pdf

17. "Microsoft Azure Website" Retrieved from URL https://en.wikipedia.org/wiki/Microsoft_Azure. Accessed Nov 2019.

18. Retrieved from URL https://www.mkyong.com/tutorials/google-app-engine-t utorial/

19. K. K. Lavania, Y. Sharma and C. Bakliwal "A Review on Cloud Computing Model", International Journal on Recent and Innovation Trends in Computing and Communication, Vol. 1, Issue. 3, pp.161-163, March 2013.

20. Retrieved from URL https://en.wikipedia.org/wiki/Cloud_computing.

21. https://www.bluepiit.com/blog/different-types-of-cloudcomputing-service-models/. 
Fakhrun Jamal et al., International Journal of Emerging Trends in Engineering Research, 8(3), March 2020, 894 - 905

22. M. Sajid and Z. Raza "Cloud Computing: Issues and Challenges", International Conference on Cloud, Big Data and Trust 2013, Nov 13-15, RGPV.

23. F. Tongke, "Smart Agriculture Based on Cloud Computing and IOT", Journal of Convergence Information Technology (JCIT), Vol. 8, No 2, Jan 2013 doi: 10.4156/jcit.vol8.issue2.26.

24. "Datacentre Architecture" Retrieved from URL https://www.cisco.com/c/en/us/td/docs/solutions/Enterpr ise/Data_Center/DC_Infra2_5/DCInfra_1.html, Accessed Nov 2019.

25. B. Dinesh and B.V. Mallu "A Review on Cloud Computing", International Journal of Engineering Trends and Technology, Vol. 4, Issue. 4, PP.803-808, April 2013.

26. "Different types of Cloud Services", Retrieved from URL

https://www.bluepiit.com/blog/different-types-of-cloudcomputing-service-models/, Accessed Oct 2019.

27. B. Singh, "A systematic Review on Cloud Computing" International Journal of Engineering Research \&Technology, Vol. 2, Issue. 2, pp. 1-8, February 2013.

28. "Distributed File System and Google file", Retrieved from

URL

https://www.sciencedirect.com/topics/computer-science/ google-file-system. Accessed Dce 2019.

29. "Google File System", Retrieved from URL https://www.sciencedirect.com/topics/computer-science/ google-file-system. Accessed Oct 2019.

30. "Hadoop and MapReduce" Retrieved from URL https://www.tutorialspoint.com/hadoop/hadoop_mapred uce.html. Accessed Oct 2019.

31. S. Ma, "A Review on Cloud Computing Development", Journal of Networks, Vol.7, No.2, February 2012.

32. "Amazon Elastic Cloud Compute" Retrieved from URL

https://en.wikipedia.org/wiki/Amazon_Elastic_Compute _Cloud. Accessed Nov 2019.

33. "Amazon Simple Storage Services" Retrieved from URL https://aws.amazon.com/s3/, Accessed Nov 2019.

34. M. Haris and R.Z. Khan "A Systematic Review on Load Balancing Issues in Cloud Computing" ICSCN 2019, LNDECT 39, pp. 297-303, 2020.

35. Retrieved from

URL http://editsworld.com/cloud-computing-services-and-mo del/ accessed on 1:25 P.m, 27 Jan, 2020.

36. Retrieved from URL http://konstantinfosolutions.over-blog.com/cloud-deploy ment-models, accessed on $30 \mathrm{Jan}, 2020$.

37. A.A Altaye, J.S Nixon "A Comparative Study on Big Data Applications in Higher Education", WARSE, International journal of Emerging Trends in Engineering Research, Vol 7, No.12, pp. 739-745, December 2019. https://doi.org/10.30534/ijeter/2019/027122019
38. E.Chandra, P. Prederikus, S.Liu, G.Wang, " Cukur 361 Mobile Application design for SME using Hadoop Framework", WARSE, International Journal of Emerging Trends in Engineering Research, Vol 7, No 12, pp. 798-804. December 2019. https://doi.org/10.30534/ijeter/2019/127122019

39. B.W.K.Malubaya, G.Wang, "Real Time Parking Information System with Cloud Computing Open Architecture Approach", WARSE, International journal of Emerging Trends in Engineering Research, Vol 8, No 1, pp. 18-22. January 2020. https://doi.org/10.30534/ijeter/2020/04812020 